\title{
Developments of rubber material wear in conveyer belt system
}

\author{
F. Hakami ${ }^{1}$, A. Pramanik*1 ${ }^{1}$ N. Ridgway ${ }^{1}$, A. K. Basak ${ }^{2}$ \\ ${ }^{1}$ Department of Mechanical Engineering, Curtin University, Bentley, Australia \\ ${ }^{2}$ Adelaide Microscopy, the University of Adelaide, Australia \\ *Corresponding author, Email: alokesh.pramanik@curtin.edu.au, alokeshpramanik@gmail.com, \\ Phone: + 61892667981
}

\begin{abstract}
Regular degradation of rubbers contribute frequent maintenance of conveyer belt system. This paper investigates wear rate and mechanisms of rubber and associated influential parameters based on the information available in literature. Abrasion, fatigue and roll formation are dominate wear mechanisms that are influenced by load, sliding velocity, hardness and friction. Correlations among influential parameters and their effect on rubber wear was established in details. Archad's equation does not work for rubber wear but researchers have proposed equations similar to that. Adhesion wear forms roll in the smooth surface when tear strength of rubber is low. Wear caused by adhesion is abrasion when surface texture is harsh. Hysteresis enhances fatigue wear if the substrate asperities are round or blunt.
\end{abstract}

Keywords: Rubber; wear mechanism; abrasion; friction.

\section{Abbreviation:}

$\begin{array}{ll}\text { AFM } & \text { Atomic force microscopy } \\ \text { EPDM } & \text { Ethylene propylene diene } \\ \text { HNBR } & \text { Hydrogenated acrylonitrile-butadiene rubber } \\ \text { PDMS } & \text { Poly dimethyl siloxane } \\ \text { PEEK } & \text { Poly ether ketone } \\ \text { PTFE } & \text { Polytetrafluoroethylene } \\ \text { PVC } & \text { Polyvinyl chloride } \\ \text { NBR } & \text { Acrylonitrile butadiene rubber } \\ \text { NR } & \text { Natural rubber } \\ \text { SBR } & \text { Styrene-butadiene rubber }\end{array}$


XNBR Carboxylate acrylonitrile butadiene rubber

\section{Introduction}

Conveyor belt is one of the primary systems used in mining and industries to transport bulk materials in continuous/semi-continuous mode $(1,2)$ over the distances of few metres to several kilometres. As the system involves number of moving components, wear and friction are inevitable and thus material transportation on conveyors is costly due to continual maintenance and replacement of wear-out components, which reflects on significant production and financial cost (2). Despite high maintenance cost, conveyor belts are being used widely in mines, ports and cement plants due to their constructive and physical adaptability. Application/choice of a suitable conveyor belt based on system's requirement is necessary for accurate functioning of the system as a whole (1). The physical/mechanical properties of the belt itself and external parameters (external load and type of materials, transmit power and motion) have effect on characteristics of conveyor belt performance (1). Most often, costs for procurement, maintenance, overhaul, and restoration of conveyor belt overshadows the costs of the rest of the system, such as, steel supports and machines attached to it, considering their respective lifetimes. Therefore, reducing these costs by enhancing the lifetime of conveyor belt system is indispensable $(2,3)$.

As evident in literature, most important factor that affect the lifetime of conveyer belt is 'wear' during material transportation. There are number of investigations on 'wear' behaviour of rubber in conveyer belt and left the scope for the researchers to study rubber's wear mechanism respective of transported materials and effective parameters such as load, speed, and friction occurring during the process. It is essential to understand the wear mechanisms of rubber and establish correlation among the available information towards the development of new technologies as well as expanding its applications. However, a complete picture on the wear behaviour of rubbers is still absent though it is imperatively needed. There are gaps in understanding on rubber wear behaviours as the information available in the literature is not well organised and linked. In addition, the latest developments in this area are not properly correlated. To address these issues, wear mechanisms of rubber and influence of different parameters such as, load, sliding speed and friction on wear process were investigated based on the information available in literature. Wear rate plays a paramount role in determining system performance and estimating belt's lifetime. Therefore, it would be possible to improve the lifespan of conveyor belt system, avoid failures, decrease downtime, and reduce overall costs by controlling various external system parameters that affect wear and wear mechanism. 


\section{Overview of conveyor belt system}

A simple conveyor belt system contains two or more pulleys, and a carrying medium (belt) that rotates around the pulleys. Figure 1(a) shows a simple conveyor belt system. Fabric conveyor belts generally comprise of a wear resistant top layer ('top cover'), a fabric carcass to provide tensile strength and toughness, skim layers for adhesion between rubber and carcass, and a bottom layer ('bottom cover') to cover the carcass and offer adequate friction to drive pulley (figure 1(b)). In practice, top layer is of special interest as it is the most stressed part of the belt and has to withstand the wear process. Depending on applications, conveyor belts are made of polymers such as PVC and rubber materials. Polymers are classified based on their chemical structures, physical properties, mechanical behaviour and thermal characteristics (4). Based on molecular structure and their physical properties, polymers are classified as Elastomers, Plastics (thermoplastics and thermosetting), and Fibers $(4,5)$. Generally, elastomers like NR, SBR, and NBR have rubber-like properties at room temperature and the term is often used interchangeably with 'rubber' (6). In comparison with other materials such as, polymers, composites, ceramics, and metals, they have notably low Young's modulus, ranged from 0.01 to 0.1 GPa, and high yield strain $(7,8)$. Usually top layer consists of polymer based materials like NR or SBR, while EPDM rubber or NBR is preferred in case of exposure to heat or oil (2).

The pulleys support and deflect the belting through conveyor structure and provide a mechanism where conveyor belt can be trained to run (track) through or along conveyor idlers. Generally, ceramic or rubber laggings cover pulleys as shown in figure 1(c) for smooth and efficient operation.

As stated previously, the main reason for failure of conveyor belt system is 'wear' resulted from direct contact with abrasive materials being transported $(3,9)$. Hard particles of transported materials cause scratches which enhance wear process and ultimately contribute towards systems' failure (10).
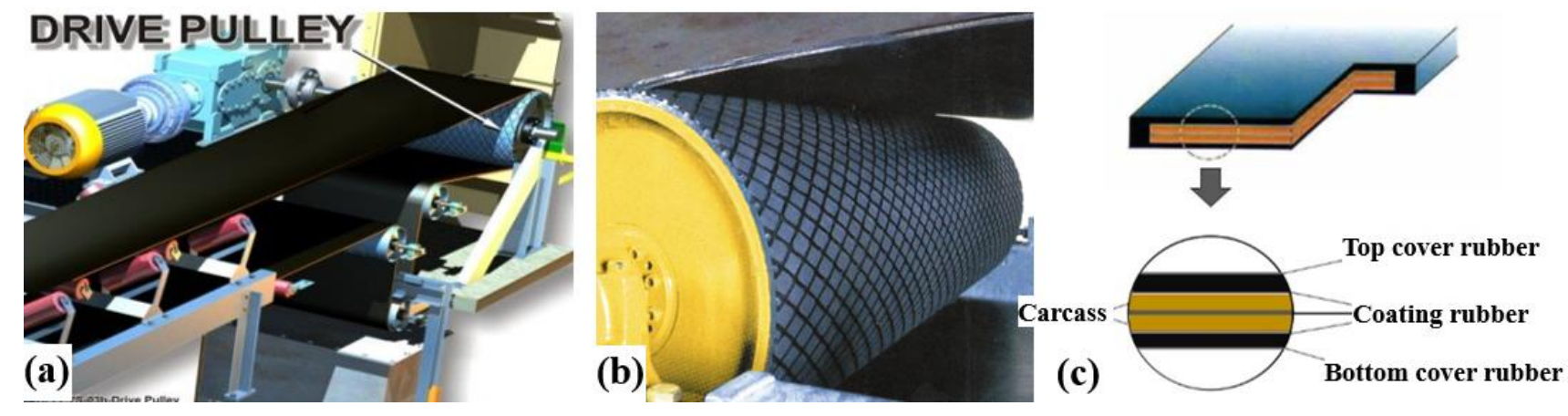

Figure 1: (a) Conveyor belt system, (b) schematic of belt structure and(c) pulley with rubber lining.

\section{Types of wear involved in conveyer belt system}

Proper selection of suitable belt conveyor types can guarantee high operational safety, high productivity of labour, simple operation and maintenance, as well as a minimum environmental impact 
$(11,12)$. Zhao and Lin (11) identified the significant fault as the conveyor belt deviation which occurs when the center lines of belt and conveyor are not in line. This takes place between belt edge and rack wear which causes premature belt edge damage, reduce the life of conveyors, affect the throughput of materials, and affects the production directly (11). According to Fedorko et al., $(13,14)$, the process of conveyor belt wearing and damaging is a restraining condition, which has a crucial impact on the operational service life of a conveyor belt. Each conveyor belt has a limited service life, determined by the wear of cover layers, amount of punctures, damage, deformation, and loss of functional properties. According to Gharahasanlou (15), a conveyor belt is an element with the highest failure probability. The large number of manufacturing, storage, manipulation, and operational activities performed during the service life of a conveyor belt are likely to lead to failures. Important factors include the methods used for conveyor belt storage. Long-term storage, which is not compliant with the applicable standards, contributes to the shortening of a belt's service life (16). Andrejiova et al., (16) noted that that for a stored conveyor belt there is a higher risk of the incidence of significant damage. During the storage period, a conveyor belt may crack as its age increases, whereas an unstored conveyor belt, put into operation, shows only usual wear. Similarly, solar radiation, high temperature, and humidity are harmful for conveyor belts. Therefore, many manufacturers warn that it is not advisable to store conveyor belts for more than three years. At present, many problems connected with the storage and with modified properties of long-stored belts may be avoided by using a non-storage management system, which efficiently solves not only the problems with conveyor belt storage, but also brings savings in costs of storage of conveyor belts and other equipment (16). The conveyor belt is subjected to a process of gradual wearing and degradation. The most common case of the conveyor belt damage is a puncture caused by falling of a sharp material (17). The degradation of joining among the individual construction layers inside the conveyor belt also damages conveyor belt (14). Another very frequently occurrence of the conveyor belt damage is a degradation influence of the heat factor. This damage occurs due to a high temperature of the transported material or because of a high ambient temperature. Rubber is a material, which is very sensitive to the temperature influences (18). The thermal damage of the conveyor belt occurs along the whole length of the belt and from this reason the conveyor belt, which is damaged in this way and cannot be repaired by a simple local removing or by a shortening of the belt. The faults on the belt top layer because of the hot transported material causes oxidative aging of the belt which causes a fission of macromolecules into the radicals resulting oxidative chain reaction (14). The conveyer belt system experiences dust generation (19), wear and erosion (14), and excessive noise (20). The dust emission is associated to the granular flow and airflow. The flow pattern of granular materials plays an important role in affecting these factors during the transportation processes of granular materials $(21,22)$. The wear on the receiving belt is more serious 
with the increase of granular material feed rate and the decrease of particle diameter. The decrease of the receiving belt speed makes the granular layer thicker, which reduces wear on the belt (23).

Wear mechanism in conveyer belt system is a complex phenomenon that depends on number of parameters such as, counterface texture, sliding distance, applied normal load, working temperature, speed and running time (24-26). A combination of processes such as, mechanical, mechano-chemical and thermo-chemical take place in service conditions (27). The problem of rubber degradation in conveyor belts is a very important question, because the conveyor belt incorporates a lot amount of rubber, which is an expensive base material (28). Therefore, the rubber wear is in the main focus of this investigation. The characteristics of rubber failure due to wear appear as shredding, tearing, pulling and rolling into a curl accompanied by local irreversible changes in elastomeric properties such as tensile strength, elongation at break and hardness (29). The most common wear mode for polymers are abrasion, adhesion and fatigue $(30,31)$ and based on that, dominant wear mechanisms of rubbers are: (1) abrasive wear, (2) fatigue wear, and (3) roll formation $(29,32,33)$.

\subsection{Abrasion wear}

The simplest form of wear caused due to friction between sliding particles against rigid materials, as what happens in conveyor belt system between belt/pulleys, belt/bulk materials is abrasive wear (27, 32). This wear occurs due to micro-cutting and longitudinal scratches because of sliding materials and tips of sharp asperities of materials in action cause tearing of belt. In the absence of any serious chemical phenomena, abrasion process initially removes small rubber chunks of few microns in size and introduce pits (34). In addition to that, when chemical/moisture are present in the environment, corrosion takes place together with wear and may enhanced the degradation process further depending on situation as described elaborately by Basak et al (35).

Abrasive wear can be categorized as two-body and three-body abrasions and a combination of both (2, 9, 36). In two-body abrasion, wear is caused by sliding of hard protuberances of one surface on the other. When a third body is introduced between two surfaces, autogenously consists of interfacial elements or foreign matter, wear is known as three-body abrasion. In this case, particles such as wear debris, lubricants, entrained particles, or even reactive chemicals are trapped between two solid surfaces and free to roll as well as slide (37). Figure 2 shows schematic picture of two body and three body abrasion wear process.

Generally, two-body abrasion often occurs during lab-scale tribological tests, whereas three-body abrasion is more often present in practical and industrial applications $(2,10,37,38)$. Investigations of 
two-body abrasion of polymeric materials have been performed more extensively than three-body abrasive wear by various investigators (39).
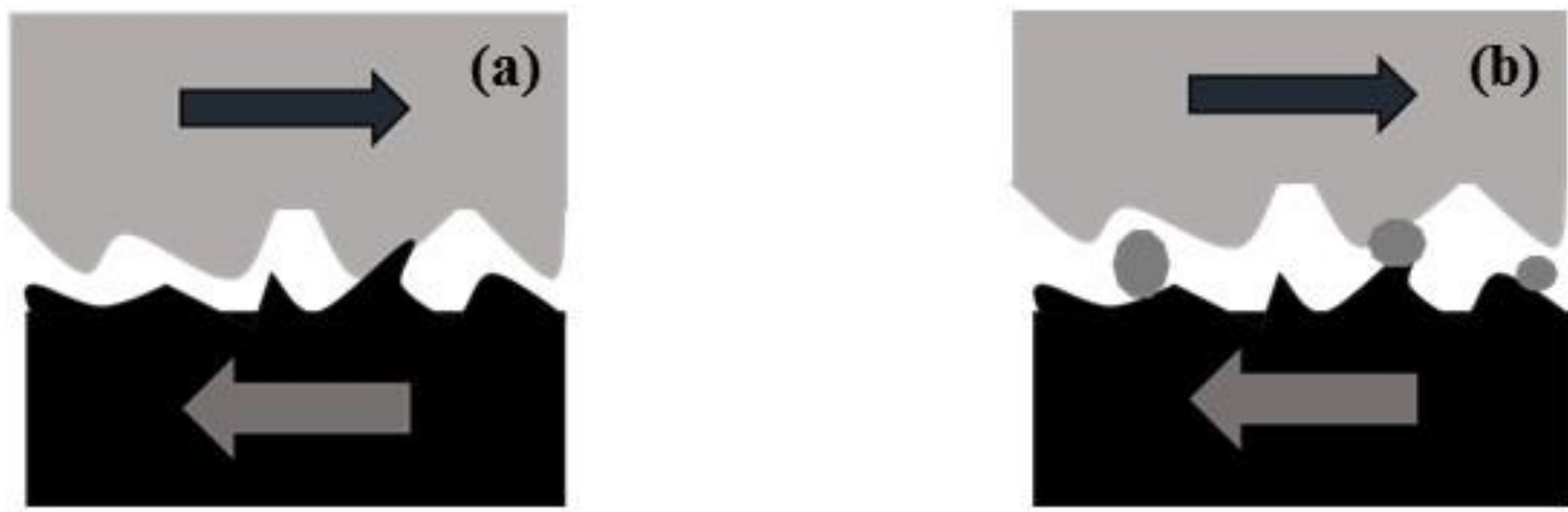

Figure 2: Schematic of (a) two-body and (b) three-body abrasive wear.

Scratches, gouges, and scoring marks are usual on worn surfaces and appearance of formed debris is similar to fine cutting chips produced during machining of metals. Deformation modes for plastic materials are categorized as grooving and cutting. Plastic grooving refers to ploughing where material is displaced sideways, forms ridges adjacent towards developing groove and is caused by the particles that are pushed ahead. Unlike grooving, in cutting, material is removed from surface and forms chip (30). Figure 3 demonstrates SEM pictures of neat PEEK surfaces abraded at different load under single pass ( $\mathrm{a}$ and $\mathrm{b}$ ) conditions. Fine wear debris are formed at lower load when wear mechanism is cutting as shown in figure 3(a). At higher load, wear mechanism is ploughing where the surface is plastically deformed and wear debris are adhered to the surface as shown in figure 3(b) (37).
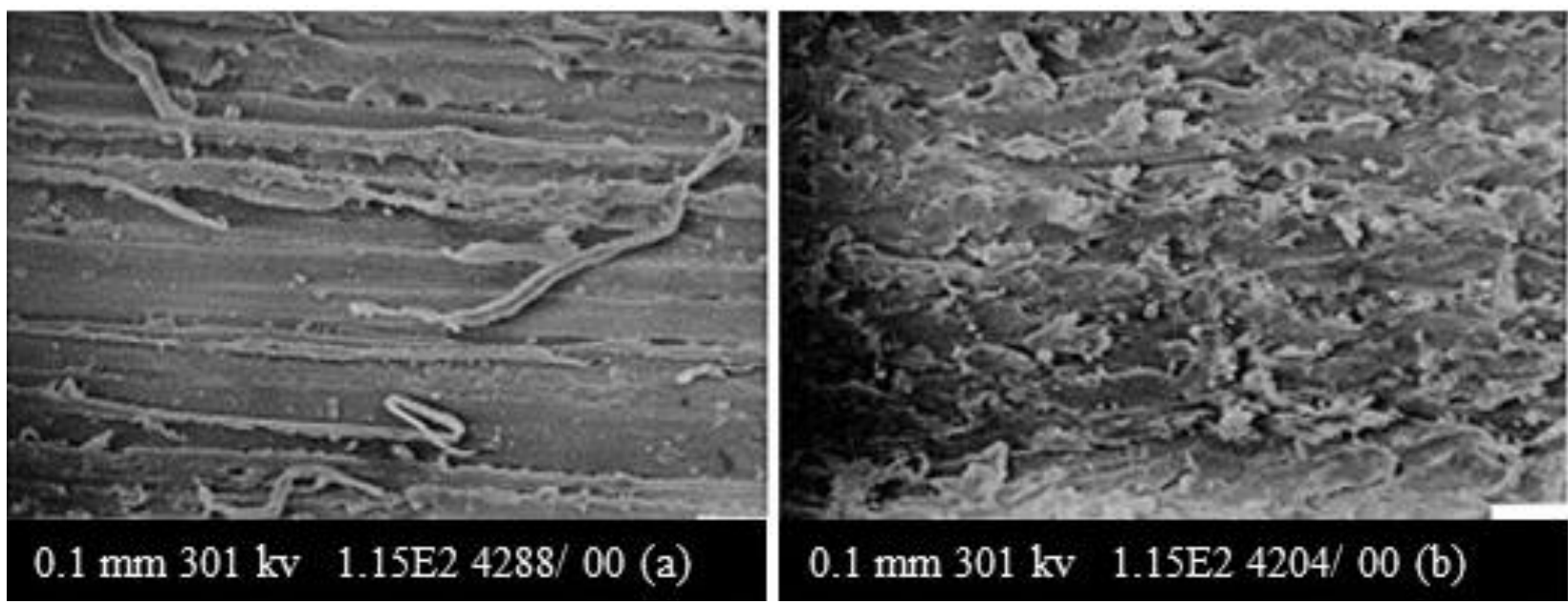

Figure 3: SEM of surfaces of neat PEEK: (a) $\mathrm{L}=4 \mathrm{~N}$; (b) $\mathrm{L}=12 \mathrm{~N}$ (two-body abrasive wear (single pass condition), $v=5 \mathrm{~cm} / \mathrm{s}, \mathrm{d}=4 \mathrm{~m}$, counterface $\mathrm{SiC}$ abrasive paper of 120 grade (grit size $\approx 175 \mu \mathrm{m}$ ) 
In addition to above mentioned process, low-stress, and high-stress are other forms of abrasion (10, 40, 41). Fragmentation of abrasive material during the process and generation of new sharp edges causes high-stress. Despite the abrasives do not split, abrasion caused by sand paper is still considered as high-stress as it remains sharp during the process. The ISO 4649 test is a good example for such a high-stress test (2). High and low stress abrasions are determined by contacting forces between abrasive and the surface being abraded (10).

\subsection{Fatigue wear}

Cyclic deformation results in fatigue wear on blunt or round shaped asperities in rubber materials. This causes small cavitation which propagate to a definite fracture (29). The mechanism is continuous but intensity is mild. Figures $4 \& 5$ illustrate schematic of fatigue wear in rubber caused by repeated applied load and crack initiation. As evident by sub-surface deformation of involved materials, maximum stress that generates cracks, develops beneath the surface $(35,42)$. Similar to metallic material, the maximum stress occurs just below the loaded surface of rubber when there is a perfect contact between blunt or round shaped asperities and rubber materials that are in relative motion. This causes the cracks to take place beneath the loaded surface $(43,44)$. The tiny cracks start at a location beneath the surface where stress is maximum. Then the cracks propagate towards free surface and join each other due to repeated fluctuating loading, and finally material separation occurs (figures 4 \& 5).

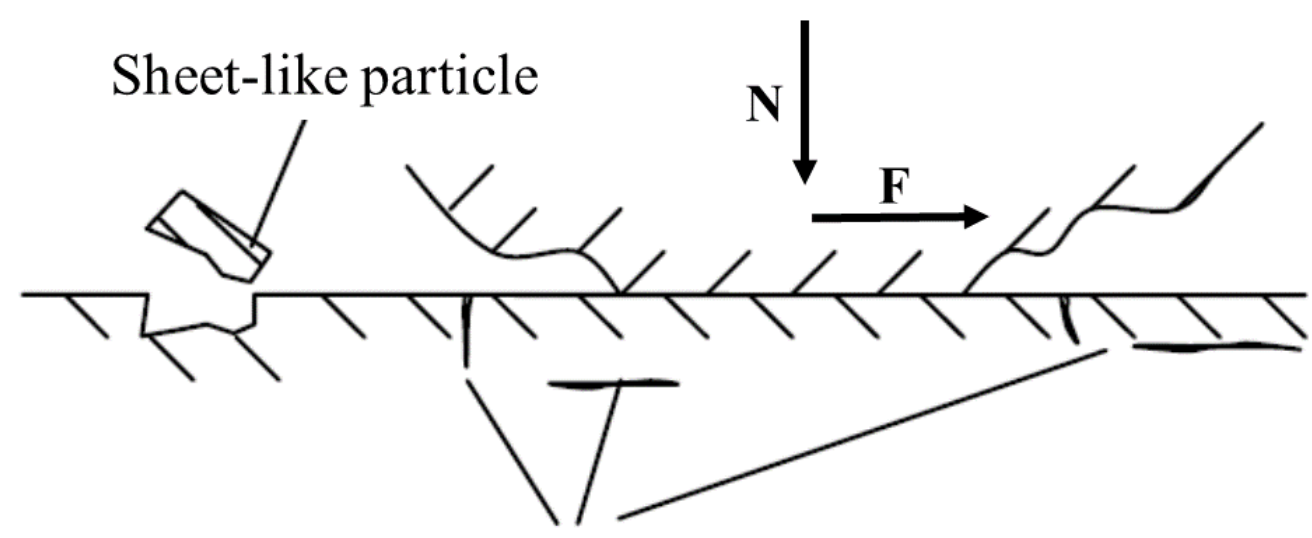

\section{Cracks}

Figure 4:Characteristics of surface fatigue wear model (42).
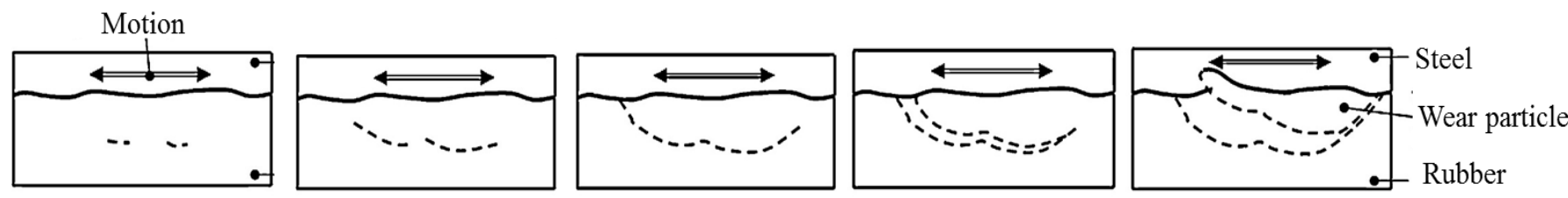

Figure 5: Characteristics of surface fatigue wear model (45). 


\subsection{Roll formation}

Wear by roll formation occurs on smooth surface of compressed rubber, which generates wave detachment at different contact area. These waves, also known as Schallamach waves, propagate across the contact zone from front to back (29) as shown schematically in Figure 6 (42). Roll formation is contributed by adhesion of rubber wave to the abrader when tear strength of rubber is low. The relative motion in the interface causes the waves of rubber due the low elastic modulus of rubber. The waves got fresh surfaces that are attached to the abrader surface due to adhesion. With the further advancement of the abrader (Fig. 6) the wave extends and the area of adhesion increases. Due to change of loading conditions along the length of waves with the further advancement of the abrader, the initial adhesion starts to release and the peak of the waves form curly shape. Finally, the waves take the shape of rolls and detached from the rubber surface with the further advancement of the abrader.

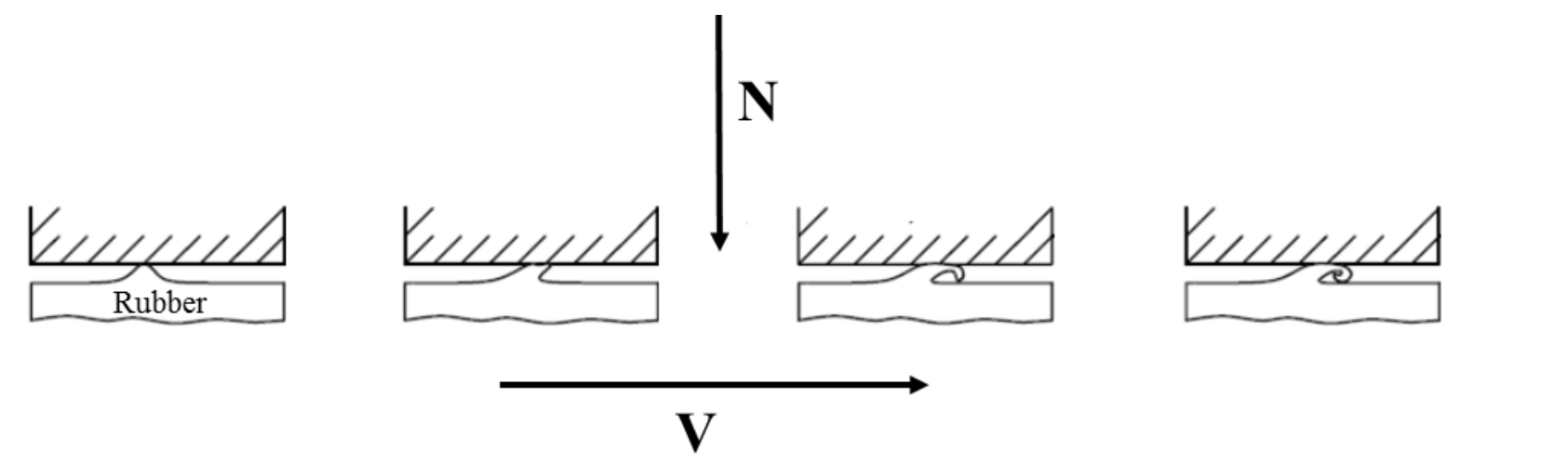

Figure 6. wear by roll formation (42).

\section{Wear mechanisms}

Failure due to abrasive wear is a major problem in number of systems that involve moving parts as well as abrasives. Abrasives enter between the components and result in abrasive wear that is generally the most costly form of wear $(3,9)$. Understanding wear mechanism is useful by linking the abrasion resistance of rubber and its mechanical properties to predict product lifespan in service and to develop lab-scale abrasion test method accordingly $(27,46)$.

Some researchers presented patterns and nature of abrasive wear of rubber. Schallamach $(47,48)$ was the first to study the failure of rubber by applying a hard projection moving over its surface. In this case, abrasion of rubber is studied by using a needle that scratched the surface under controlled conditions (49). Rubber abrasion is explained as mechanical failure that forms periodic surface pattern termed as "abrasion pattern", which are also known as Schallamach wave after his name (46). 
During abrasion wear, a series of parallel ridges are created on rubber surface that is perpendicular to sliding direction. As needle passes over, a complicated compression-tension strain is generated and the cross-over from compression to tension causes the folds with the relaxation of rubber and turn back of folds as abrasive pattern is created (50). Stretches and twists of rubber's molecular chains make this possible. During sliding of surfaces against each other, shear stress develops and when it exceeds the cohesive strength of molecular chain of rubber, fracture happens. Because of the repeated loading, stored internal damping energy is released through surface crack. Therefore, deformed molecular chains want to return to their original position and shape. However, because of rubber's visco-elastic nature, it does not return to the exact or original position (46). It forms initial stage of abrasive wear, and spread until reaching a constant pattern just like ripples in water. Abrasion rate increases with progressive development of wear pattern and therefore, wear rate is not constant until a stable pattern is formed (51). Figure 7 shows abrasion pattern for EPDM rubber (50) and the orientations of the patterns are used as tool for diagnosis abrasion direction (34).

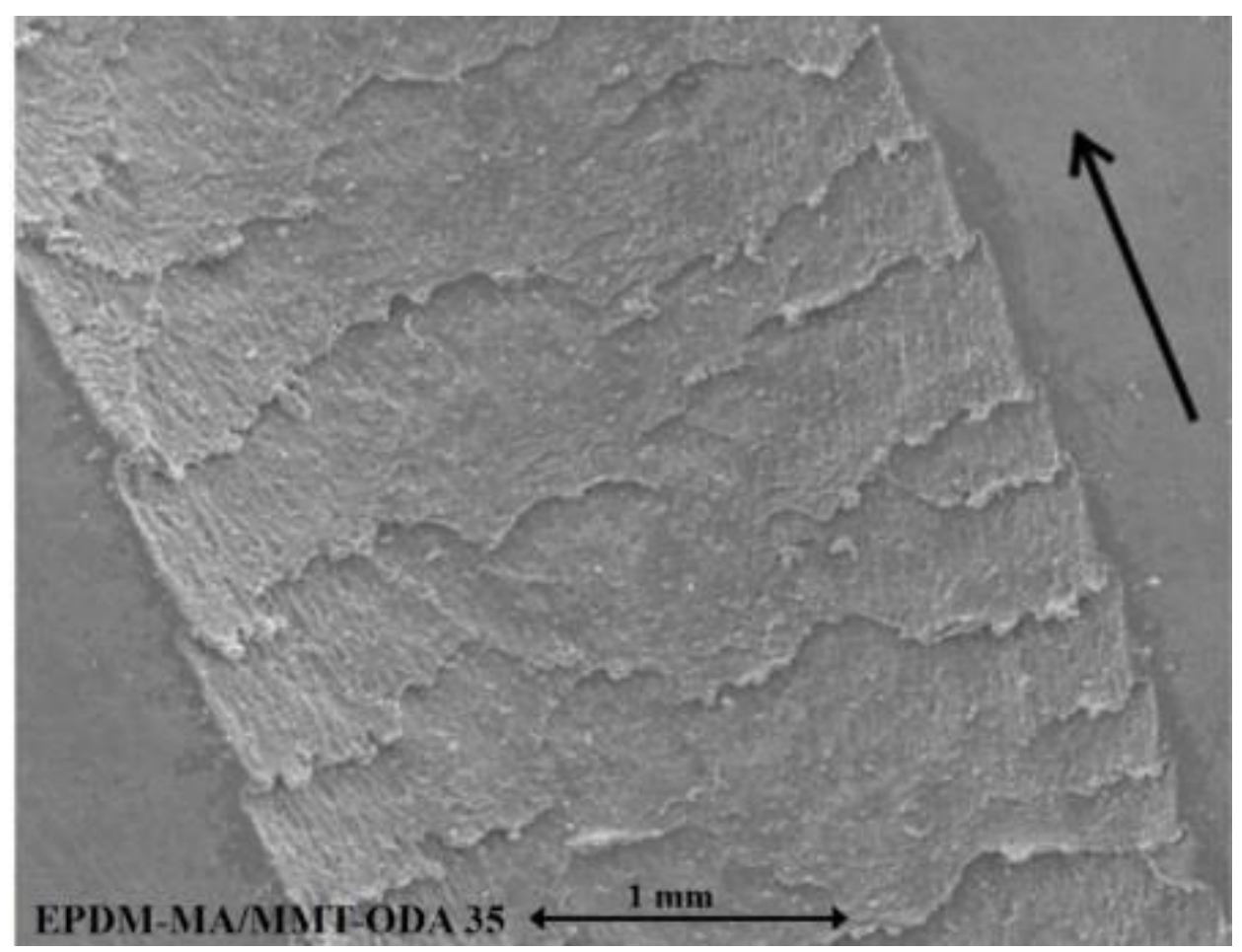

Figure 7: Abrasion pattern of EPDM rubber (50).

Increase in temperature in contact area during sliding is usual and high temperature influences resistance of rubber to abrasion negatively (52). Following the needle scratch experiments of Schallamach (49), a mechanism is proposed by Champ et al. (53) and others $(34,54,55)$, which relates wear rate to fatigue crack growth rate and characteristics by using a fracture mechanics approach. The altering driving force of the whole belt, the bending and stretching behavior around the pulley may 
contribute to the fatigue. Though Schallamch's technique provides insights into nature of abrasion process, removal of only small amount of rubber during each run and complex stress in contact area of needle and rubber are limitations of such experiments. To overcome that (56) a line contact test is developed (53) by replacing the needle in Schallamach's model with a blade. It was noted (53) that, concentration of stress in abrasion pattern leads to occurrence of crack growth in rubber and there (57) is a relation between cyclic crack growth and stored energy release rate. Southern and Thomas (58) measured wear rate during steady-state growth conditions using average rate of mass loss from the wheel per cycle and by measuring the rate of advancement of individual ridges over the surface. For predicting fatigue crack growth of elastomers, this standard technique (razor blade abrader) has been widely adopted and extended to examine physical or chemical process in rubber abrasion by researchers $(54,55,58)$.

Fukahori et al. $(51,56,59-61)$ used fracture mechanics to explain the formation of abrasion pattern in rubber by relating two kinds of periodic motions: micro-vibration generated during slip stage of stickslip motion and stick-slip oscillation. Cracks initiate in slip region of rubber surface but propagate in stick region. In addition, micro vibration provides driving force to initiate cracks. As a result, at first stage, natural period of rubber and sliding velocity determine the abrasion pattern spacing. After critical number of sliding, however, final and constant pattern's size agrees with distance that is specified by period of stick-slip oscillation and sliding velocity. Accordingly, a bimodal size distribution of abraded particles is generated during rubber abrasion. Hence, microvibration generates small particles and stick-slip oscillation generates large particles. This wear mechanism was confirmed for SBR, unfilled and filled natural rubber. Coveney et al. (62) performed some tests by blade abrader on a vulcanised natural rubber to examine their hypothesis and their observation. Similar ridged pattern after heavy abrasion was confirmed. However, bursts of high frequency acceleration were not found before heavy abrasion, which is in contrast with their idea that abrasion is caused by micro-cracks produced by high frequency vibration.

Watson et al. (63) used AFM on the surface of a soft elastic polymer (PDMS) to observe stick-slip. Figure 8 illustrates topographical and lateral force image during manipulation cycle that stick-slip is happening. The formed stick lines and the path taken by the tip during the slip stage (arrows) are evident. Fukahori et al. (51) simulated crack initiation process by FEA which is confirmed by experiments that micro-vibration during slip stage enhances crack initiation in rubber abrasion. The cracks originate where maximum tensile stress occur and its angle with surface is between $30^{\circ}$ and $50^{\circ}$ and decreased with propagation of crack. For determining abrasion rate of rubber, angle at crack-tip 
is very important, as investigated by Busfield et al. (64) and obtained results from experiments were in agreement with crack growth prediction rate by FEA. The angle and crack growth rate increases with increase of load.
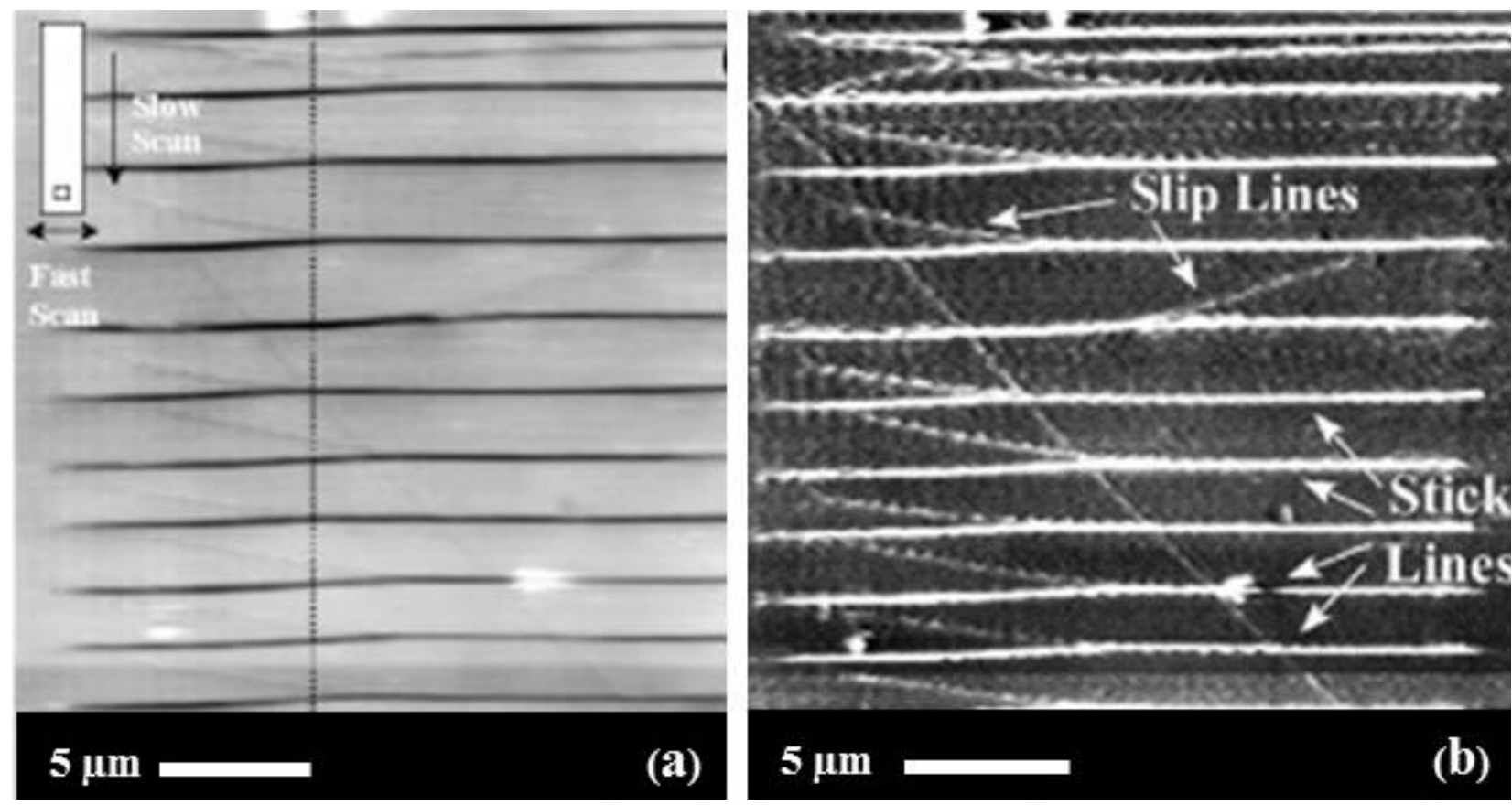

Figure 8: (a) Topographical and (b) lateral force image of the manipulated region carried out with a soft lever (63).

In case of 3-body abrasion, a third body is also present, which consists of interfacial elements either created autogenously or foreign matter introduced into the system such as, wear debris, lubricants, entrained particles or even reactive chemicals (65). Three-body abrasion is more often present in practical applications (66-68). Molnar et al., (69) compared the two-body (ISO 4649) and three-body (ASTM G65) wear of rubber based conveyor belt and compared the wear pattern with the that used in the industries. It was noted that the wear a conveyor belt experiences a mixture of more than one wear mechanism. The rim regions were riddled with large cracks, while the centre exhibits a much smoother surface due to the influence of transported goods and scrapers as shown in figure 9. The cracks were attributed to oxidative hardening and constant toughing, and abrasion was absent in the rim region. This was due to higher hardness in the crack-filled rim regions, where the material was not abraded and was therefore subjected to hardening by oxygen uptake over its entire lifetime. There was no crack in the centre region and this surface was very smooth with clear signs of abrasion. Practically all abrasion losses on this conveyor belt can be attributed to tribological interactions with the transported goods and the scrapers used to clean the belt. A closer investigation of the centre (revealed a small number of grooves perpendicular to the running direction, but also large areas covered by small pits. 
These roughened areas are characteristic for fatigue wear, which originates from continuous rolling abrasive and stretching of the material, but only affects the material surface and regions very close to it (70). This usually initiates and propagates cracks, but there were no large cracks found in the central region. It seems that the abrasion rates in the centre exceed the rate of crack propagation and thus prevent larger cracks. The ASTM G65M test, on the other hand, leads to a 3-body abrasion mechanism, which is mainly based on fatigue. This is much more similar to practical applications. So the main wear mechanism present in the centre of the belt can be seen as 3-body abrasion, where the rolling transported goods are the rolling abrasives, and to a lesser extent as 2-body abrasion, where particles of the transported goods stick to the scrapers and form the fixed abrasive. The interaction between the bare scrapers and conveyor belt can be seen as 2-body abrasion as well.
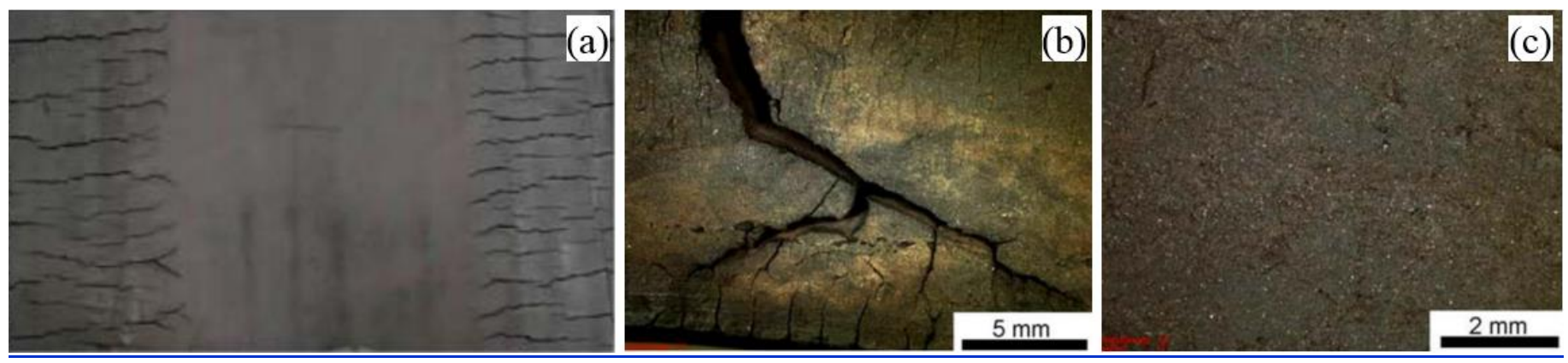

Figure 9: Wear of conveyor belt after eight years of service: (a) deep cracks in the rim region (b)

Side view of a crack in the rim region, and (c) top view of the centre region (69).

\section{Effect of different parameters on wear}

Archard's equation (71) is a model, which generally used to describe adhesive wear of metal, is also very useful in abrasive wear. The general form of the equation is:

$\mathrm{V}=\mathrm{K} \frac{\mathrm{Fd}}{\mathrm{H}}$

Where, $\mathrm{V}$ is wear volume, $\mathrm{F}$ is applied load, $\mathrm{d}$ is sliding distance, $\mathrm{H}$ is hardness of material and $\mathrm{K}$ is a constant referred to as wear coefficient. Equation (1) states that wear volume is directly proportional to normal load and sliding distance, and it is inversely proportional to hardness. Though, in some cases, a linear trend is observed for polymers and their composites, some authors considered that this equation does not hold good (72) due to effect of mechanical properties and experimental parameters such as compression strength of material and roughness, on abrasive wear of polymers and composites (37, 73). However, the relation between volume loss and compression is weaker than that of hardness effect. Effect of surface roughness on wear rate is less on rigid polymers. At lower speeds, wear rate of polymers is proportional to load, since heat generation is negligible. However, at higher speeds frictional heat increases that affects proportion of load and wear rate of polymers and deformation 
will not be entirely plastic anymore (74), which results in energy dissipation (75). Therefore, the relation between wear rate and load will not be linear. Figure 10 shows changes in different parameters with temperature in the case of an amorphous polymer (74).

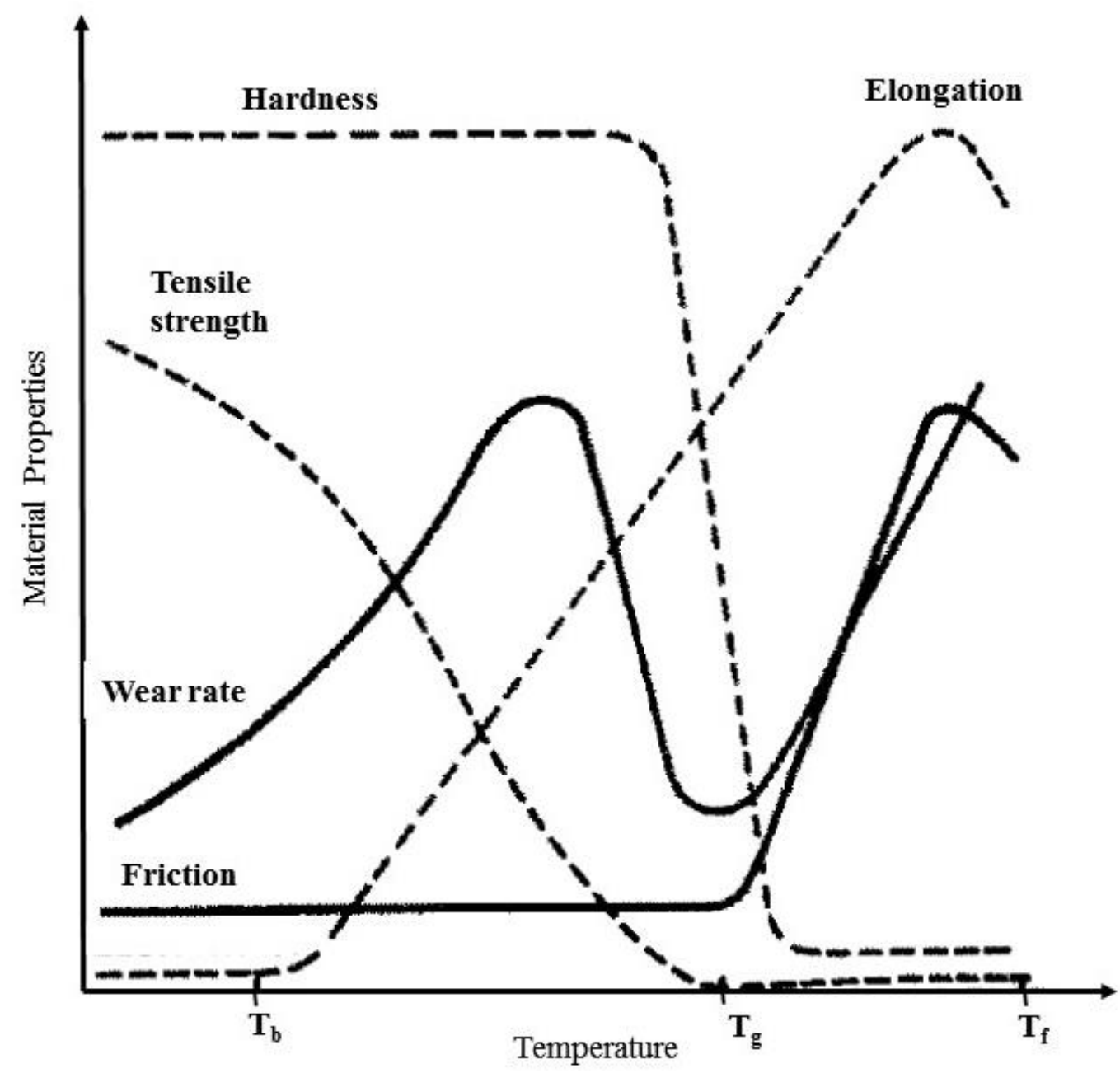

Figure 10: Schematic variation of hardness, tensile strength, elongation, friction and wear rate with temperature (74).

To investigate the effect of load and speed on wear rate, three set of rubber compounds with different compositions of XNBR and NR in addition with filler particles were tested under varying loads by Pal et al (32). Table 1 shows rubber composition and physical properties of studied specimens and for different rubber materials. In this case, increase of load enhanced wear rate for all the specimens. The tensile strength and dynamic co-efficient of friction of sample containing $80 \mathrm{wt} \%$ of XNBR was high compared to other samples by $2 \%$ and $10 \%$ respectively. The rate of wear for $\mathrm{MC}-1$ rubber vulcanizates against hard and soft rock surfaces decreases with the normal load, N. However, an opposite trend was noted for the MC-2 and MC-3 samples where the loss of the volume,

$V=\beta \cdot N^{\alpha}$ 
The values of $\alpha$ and $\beta$ depend on the properties of rock and rubber. The dynamic co-efficient of friction $(\mu)$ of NR-XNBR increases with the normal load. The co-efficient of friction is higher for $80 \mathrm{wt} . \%$ XNBR with 20 wt.\% NR vulcanizates. The wear rate of rubber against hard and soft rock surface can also be correlated with the frictional work, $F_{w}$, where volume loss,

$\mathrm{V}=k .\left(F_{w}\right)^{n}$

Constants $k$ and $n$ depend on the chemical composition and hardness of rock and rubber surfaces. For MC-1, $k$ decreases and $n$ increases but an opposite trend of $k$ and $n$ is noted for softer MC- 2 and MC3 with the increase of rock hardness. It was also observed that sample containing $80 \mathrm{wt} . \%$ of XNBR exhibits higher ridge spacing compare to other samples.

Table 1. Rubber specimens' composition and physical properties (32).

\begin{tabular}{|c|c|c|c|c|c|c|c|c|c|c|c|c|c|}
\hline $\begin{array}{c}\text { Sample } \\
\text { No. }\end{array}$ & \multicolumn{9}{|c|}{ Ingredients } & $\begin{array}{l}\text { Hardness } \\
\text { (shore A) }\end{array}$ & $\begin{array}{l}\text { Tensile } \\
\text { stress } \\
(\mathrm{MPa})\end{array}$ & $\begin{array}{c}\text { Tear } \\
\text { strength } \\
(\mathrm{N} / \mathrm{mm})\end{array}$ & $\begin{array}{c}\text { Elongation } \\
\text { at break } \\
(\%)\end{array}$ \\
\hline & $\frac{a}{n}$ & 奌 & 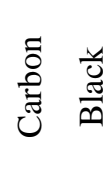 & 这 & 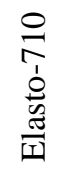 & g & $\frac{\bar{\Xi}}{\frac{D}{Z}}$ & ڤै & 온 & & & & \\
\hline MC-1 & 80 & 20 & 40 & 2 & 2 & 1 & 2 & 0.7 & 5 & 75 & 8.27 & 40.07 & 119.2 \\
\hline MC-2 & 50 & 50 & 40 & 2 & 2 & 1 & 2 & 0.7 & 5 & 70 & 3.91 & 22.70 & 171.6 \\
\hline MC-3 & 20 & 80 & 40 & 2 & 2 & 1 & 2 & 0.7 & 5 & 64 & 1.38 & 58.30 & 76.80 \\
\hline
\end{tabular}

According to Harsha and Tewari (37), wear volume increases linearly with increase of sliding distance and load in two-body and three-body abrasive wear, though the trend is not linear under multi pass during two body abrasive wear. It could be due to the transfer of polymer film of abrading surface and trapped debris in multi-pass conditions. Such transfer films and wear debris are caught in the crevices or depressions leading to clogging effect. In the case of single pass and three-body abrasive wear, polymer specimen always faces fresh abrasive particles; hence wear volume increases linearly with sliding distance and load $(37,41)$. Fukahori et al. (61) represented a relation between abrasion loss rate $(\overline{\mathrm{V}})$ (in volume) and normal load (P) for natural rubber according to Equation (4):

$\overline{\mathrm{V}}=\mathrm{k}_{4} \mathrm{p}^{\alpha}$ (4) 
Where $\mathrm{k}_{4}$ is constant. The compound and sharpness of wear tracks have influence on power index $\alpha$ and it is more than unity at stable abrasion. Equation 4 indicates that normal load is indirectly connected to abrasion loss rate(61) as shown in figure 11 in the case of NR2 (61).

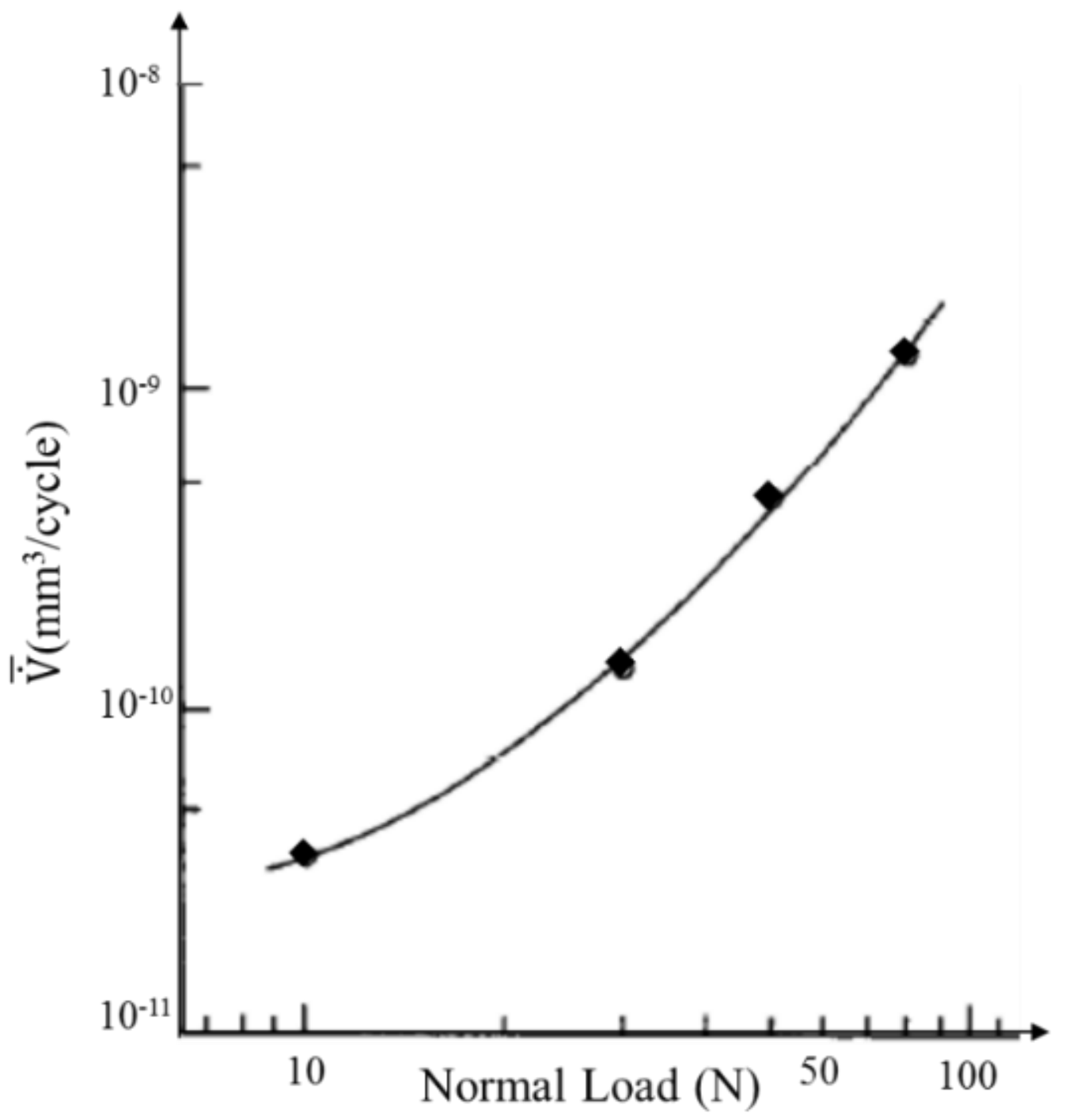

Figure 11: Relation between abrasion wear and normal load during three-body abrasion test on NR2

Other researchers who studied different polymeric materials confirmed the effect of load and sliding distance on wear resistance of materials and their composites. The results confirmed the increase of abrasive wear when the load and sliding distance are enhanced, penetration of hard asperities of counter surface to softer pin surface increases, and the deformation and fracture of asperities of softer surface increases $(76,77)$. Figure 12 demonstrates an increased wear rate of SBR with normal load (78). At higher loads, wear rate is dramatically high in comparison with lower loads, which is due to the change of wear mechanism from mild abrasive wear to severe abrasive wear. Figure 13 illustrates SEM images of SBR abraded surface for different loads. When applied load is increased, because of severe 
elastomer deformation and enhance of real contact surface, cracks disappear and ridges and grooves became more obvious.

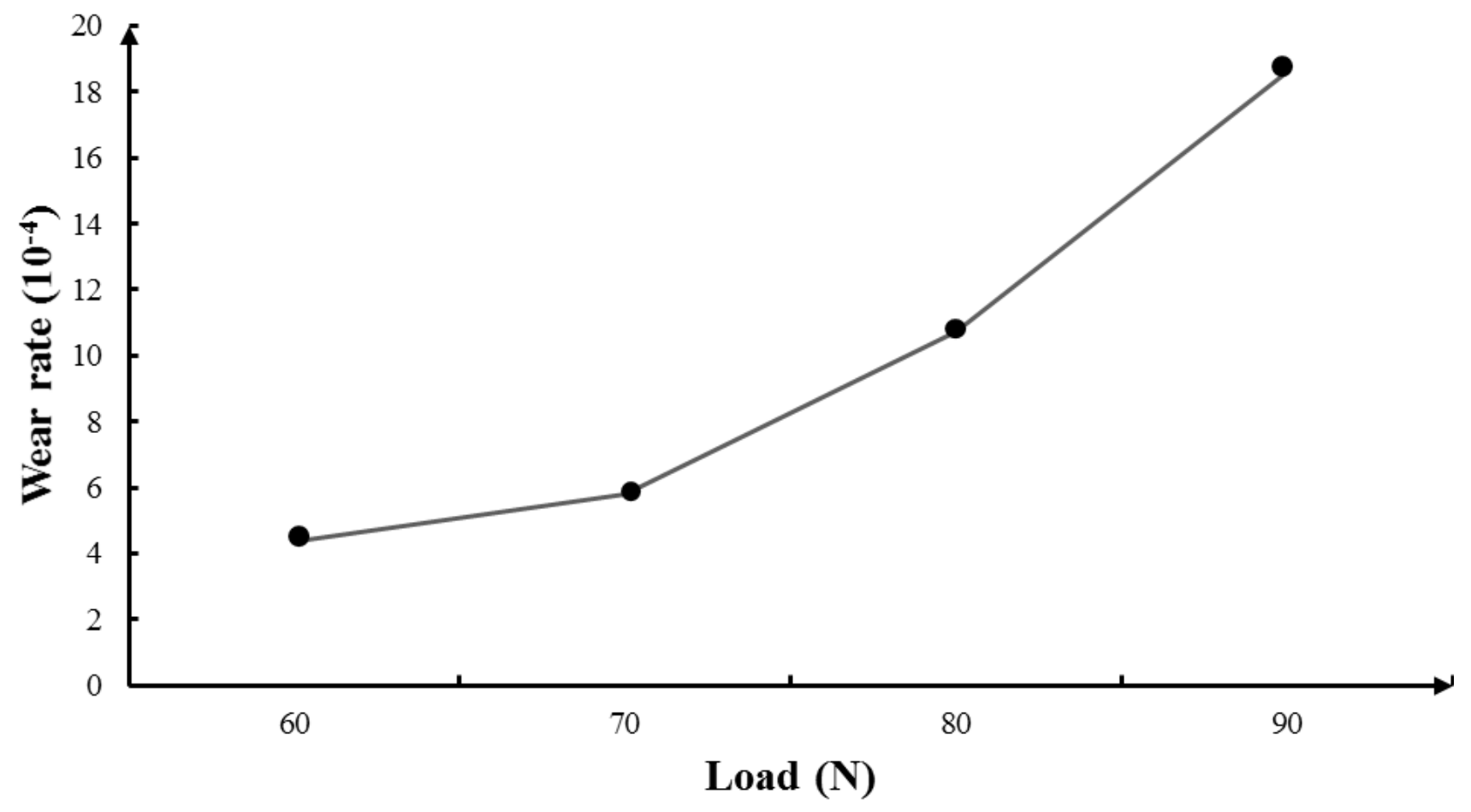

Figure 12: Wear rate of SBR for different loads (78).
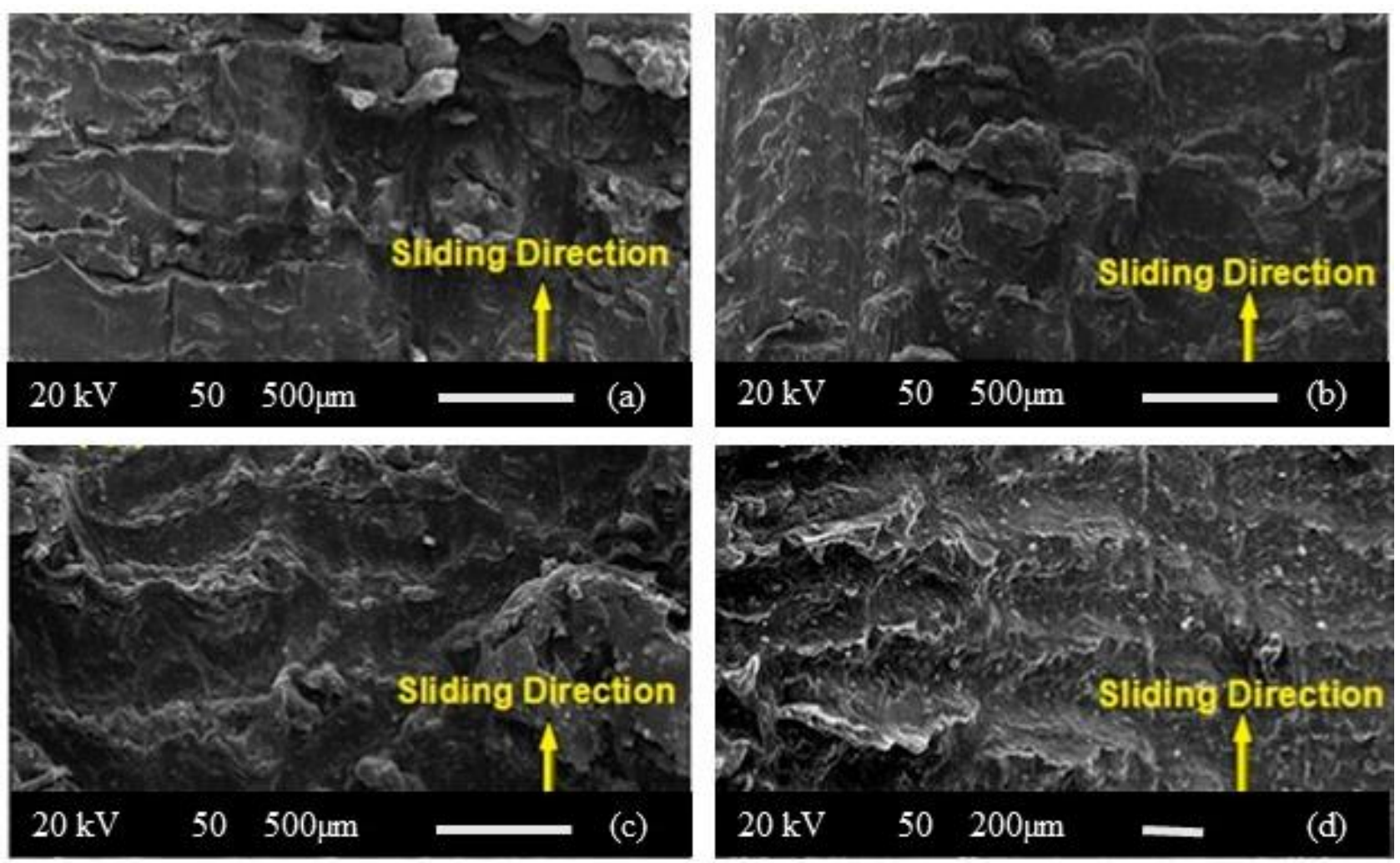

Figure 13: SEM images of abraded SBR for different loads: (a) $60 \mathrm{~N}$, (b) $70 \mathrm{~N}$, (c) $80 \mathrm{~N}$, (d) $90 \mathrm{~N}$ (78). 
Recently, Sahin (73) showed that in addition to load and sliding distance, compressive strength of materials has effect on wear resistance, as weight loss reduces with increase of compressive strength. Budinski (79) studied three body abrasive wear of 21 different kinds of polymers (not rubber) and could not find any relation between material properties (hardness, friction and scratch resistance) and abrasive wear. In contrast, many researchers have reported that mechanical properties of materials and test methods affect abrasive resistance of polymeric materials $(2,37,80)$. For example, for PEEK and its composites, wear rate decreases with increase of tensile stress (39). The mass loss of PEEK-PTFE enhances, when counter face roughness increases (80). Besides, the effect of surface roughness on wear rate is more obvious, when the polymer is rigid. In wear process of rubber like polymers, plastic deformation and cutting are less important. Figure 14 depicts material detachments and cutting on worn surface of EPDM (46). It is concluded that, with decrease of elastic modulus, type of abrasive wear mechanism changes from cutting to fatigue, and rubbers adhesion and tearing are most important type of abrasive wear (74).

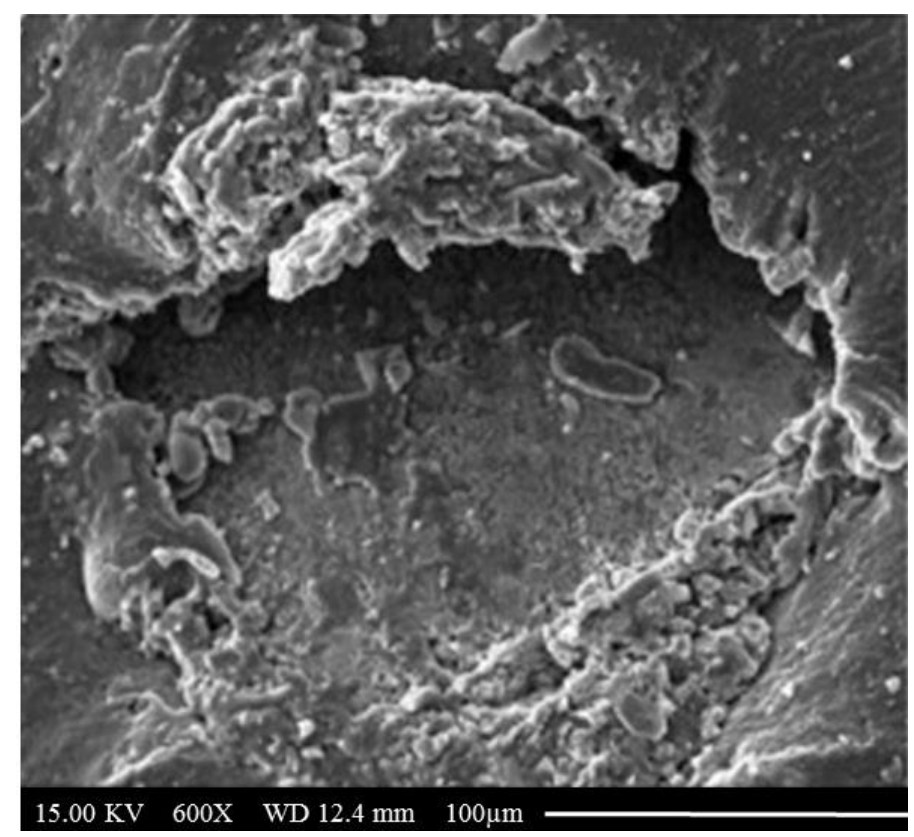

Figure 14: SEM images of EPDM worn surface (46).

Molnar et al. (2) studied the effect of characteristics, morphological and mechanical properties of SBR rubber used in conveyor belt under two and three body abrasive wear. They reported that, three-body samples experience lower abrasion, which is caused by rolling and round particles. Hence, wear mechanism is fatigue. On the other hand, because wear is caused by very sharp and fixed abrasives under two body abrasion, wear rate is higher and wear mechanism is abrasion and rupture (2). Besides, regression analysis showed that tensile strength and hardness are more effective on two-body test, while tear strength was most influential factor for three-body test. Figure 15 shows the correlation between abrasion wear rate and mechanical properties of five rubber samples. By comparing lab scale 
test results with wear of conveyor belts system, the authors concluded that, three body abrasion test better reflects what happen in practical situations (2).
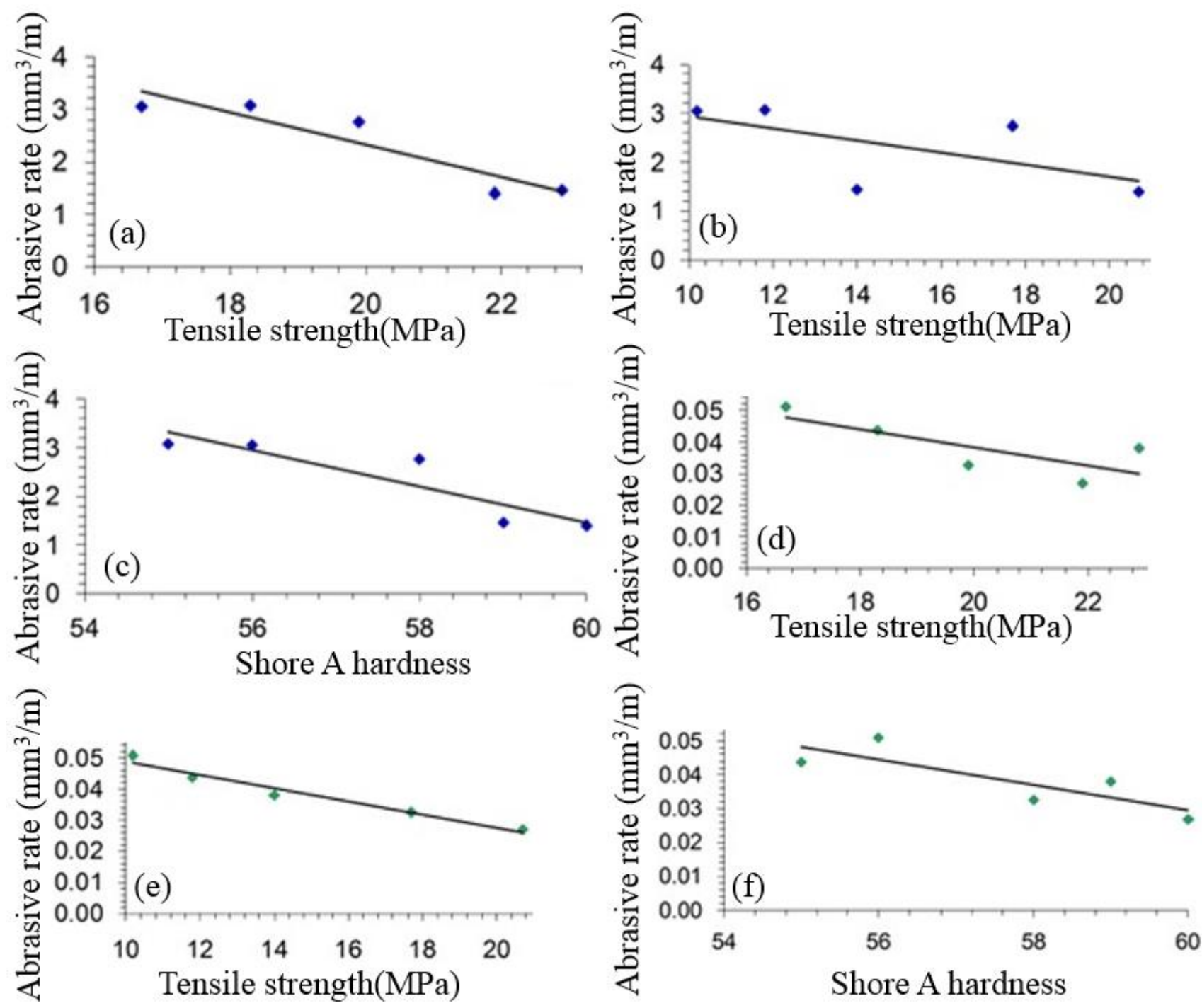

Figure 15: Correlations between mechanical properties (tensile strength, tear strength and Shore A hardness) of rubbers and abrasion rates of two body (a-c) and three body (d-f) tests (2).

During mechanical experiments on rubber, like conveyor belt system, frictional force consists of adhesion and hysteresis. Adhesion and hysteresis are caused by the surface and internal friction, respectively (81-83) and increase wear effects according to surface conditions. If the surface is smooth, adhesion will produce roll formation, especially, when tear strength of rubber is low. On the other hand, when surface texture is harsh, wear caused by adhesion is abrasion. If the surface texture of substrate is such that its asperities are rounded, hysteresis enhances fatigue wear (84). Figure 16 shows relation between friction and wear for different tread rubber materials (84). It illustrates when friction coefficient is less than critical amount, wear mechanism is fatigue that causes little wear. For friction coefficient greater than critical amount, wear mechanism is abrasive or roll formation. 
Researchers have studied the friction of rubbers under different conditions (29, 33, 85, 86). For instance, Felhös et al. (86) indicated that with increasing silica content in HNBR, wear resistance and friction coefficient enhances for a pin (steel)-on-plate (rubber) wear test. Wear behaviour of rubber compounds with various blends of XNBR and NR was investigated by Pal et al. (32) and a correlation between coefficient of friction and wear was reported. Under same experimental conditions, samples with lower friction coefficient have higher wear rate (32).Wu et al. (78) mentioned that applied load increases and friction co-efficient reduces, while wear rate enhances. However, their work shows a reverse relation between co-efficient friction and wear rate. In contrast, Muhr (34) mentioned that frictional forces (adhesive and hysteresis) necessarily do not contribute to abrasion of rubber.

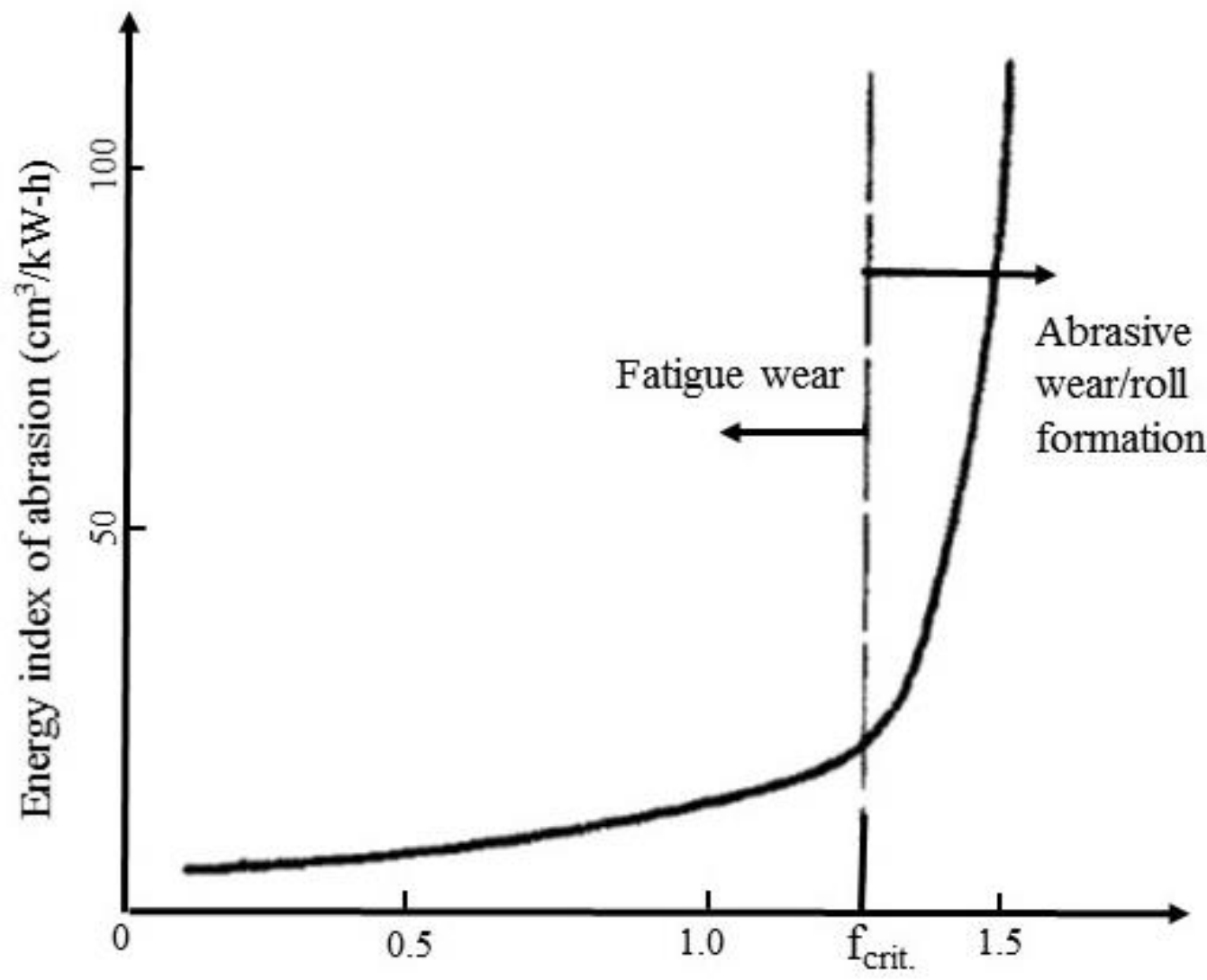

Coefficient of Friction (f)

Figure 16: Broad correlation of friction and wear(84).

Pal et al., (32) reported that amount of contact area (rubber's contact) with asperity has effect on pressure dependence of friction. In addition, asperity's geometry highly influences friction coefficient. Hysteresis friction coefficient enhances with speed until a maximum value is reached and then reduces if the speed continues to increase (87). Figure17 illustrates enhancement of normalized 
sliding speed ( $\tau \mathrm{C} / \mathrm{L})$ 's effect on the coefficient of hysteretic friction of rubber $(88)$ and reported that, maximum value depends on the nature of texture.

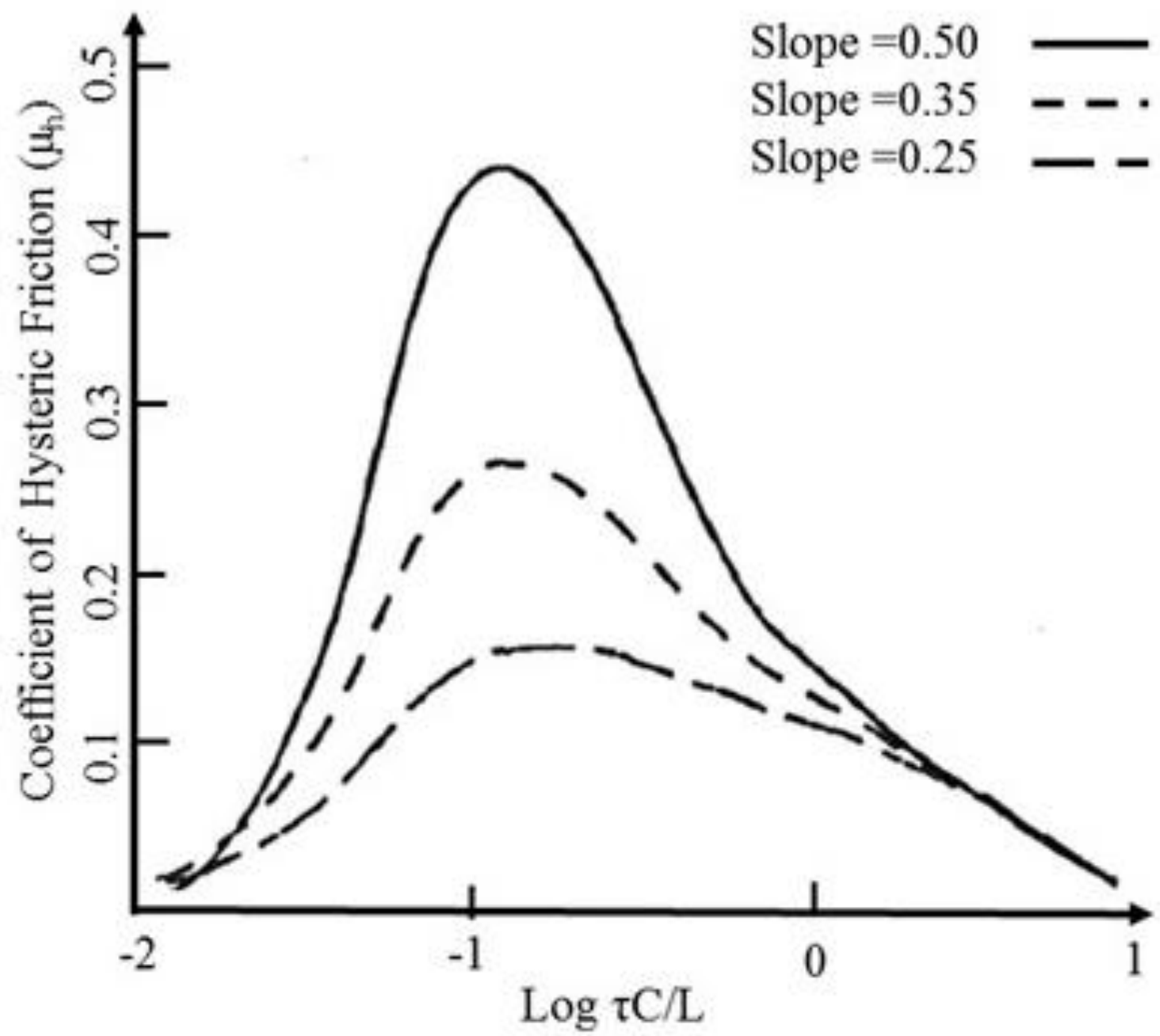

Figure 17: Speed-Friction curves at normalized average pressure of 0.075 for triangle slopes 0.25 , 0.36 , and $0.50(88)$.

\section{Summary}

The wear mechanism of rubber and influence of different parameters on wear mechanism and wear rate of rubber materials have been investigated in this study based on the information available in the literature. In most cases, the wear mechanism and wear rate of materials are correlated with different parameters such as load, sliding distance, friction, and mechanical properties of rubbers such as, tensile and tear strengths. The rubber wear mechanism and effective parameters rationalize the damage of conveyor belts and other systems where rubber is used.

Common wear types are abrasive wear, fatigue wear and roll formation for rubbers and rubber like materials. These forms periodic surface pattern perpendicular to the sliding direction on surface of 
rubber because of the visco-elastic nature of rubbers. Micro vibration and stick-slip oscillation are two driving force that cause periodic patterns. The cracks initiate in the slip region of the rubber surface, but propagate in the stick region. Wear rate is correlated to crack growth by fracture mechanism approach. Adhesion wear forms roll in the smooth surface when tear strength of rubber is low. Wear caused by adhesion is abrasion when surface texture is harsh. Hysteresis enhances fatigue wear if the substrate asperities are rounded.

Researches confirmed that applied load, sliding distance, and velocity affect wear rate of rubber. When these parameters enhances, volume loss increases. In addition, studies showed material's mechanical properties, like hardness and tensile stress, have effect on wear behaviour of rubbers. Increase of those parameters result in decrease of wear rate. Moreover, friction forces and friction coefficient influence wear mechanism according to surface conditions. Consequently, lifetime of the belt can be improved by controlling these parameters.

Archard's equation is not valid to predict the rubber wear due to very low elastic modulus and significant dependence of material properties on temperature. However, similar equations have been developed by different researchers to model the wear behaviour of rubbers. In these equation only one input parameter such as, normal force or frictional work, is included and several constants are considered which depend on the properties of rubber and abrader.

The main wear mechanism in conveyor belt system is three body abrasion wear. However, most studies about wear mechanism and effective parameters on wear of rubber have been done in two body conditions. Consequently, future investigations are necessary on three-body wear of rubber for accurate simulation of actual service condition.

\section{References}

1. Fedorko G, Molnar V, Dovica M, Toth T, Kopas M. Analysis of pipe conveyor belt damaged by thermal wear. Engineering Failure Analysis. 2014;45(0):41-8.

2. Molnar W, Varga M, Braun P, Adam K, Badisch E. Correlation of rubber based conveyor belt properties and abrasive wear rates under 2- and 3-body conditions. Wear. 2014;320(0):1-6.

3. $\mathrm{Xu} \mathrm{L}$, Vose C, StJohn D. Abrasive wear study of selected white cast irons as liner materials for the mining industry. Wear. 1993;162-164, Part B(0):820-32.

4. Thomas S, Yang W. Advances in Polymer Processing: From Macro- To Nano- Scales: Woodhead Publishing; 2009.

5. Ghosh P. Polymer Science and Technology: Plastics, Rubbers, Blends and Composites. second ed. New Delhi: Tata McGraw-Hill Education; 2001.

6. $\quad$ Franta I. Elastomers and rubber compounding materials: Elsevier; 1989. 
7. McKeen LW. 12 - Elastomers and Rubbers. The Effect of UV Light and Weather on Plastics and Elastomers (Third Edition). Boston: William Andrew Publishing; 2013. p. 299-370.

8. Materials Data Book. Cambridge University Engineering Department 2003.

9. Petrica M, Badisch E, Peinsitt T. Abrasive wear mechanisms and their relation to rock properties. Wear. 2013;308(1-2):86-94.

10. Budinski KG. Adhesive transfer to abrasive particles in abrasion testing. Wear. 2011;271(9-10):1258-

63.

11. Zhao L. Typical failure analysis and processing of belt conveyor. Procedia Engineering. 2011;26:942-

6.

12. Guo YC, Cheng G, Hu K, Wang ZF, editors. Research on the idler spacing of belt conveyor. Applied Mechanics and Materials; 2012: Trans Tech Publ.

13. Fedorko G, Molnar V, Živčák J, Dovica M, Husáková N. Failure analysis of textile rubber conveyor belt damaged by dynamic wear. Engineering failure analysis. 2013;28:103-14.

14. Fedorko G, Molnar V, Dovica M, Toth T, Kopas M. Analysis of pipe conveyor belt damaged by thermal wear. Engineering Failure Analysis. 2014;45:41-8.

15. Gharahasanlou AN, Mokhtarei A, Khodayarei A, Ataei M. Fault tree analysis of failure cause of crushing plant and mixing bed hall at Khoy cement factory in Iran. Case studies in engineering failure analysis. 2014;2(1):33-8.

16. Andrejiova M, Grincova A, Marasova D. Measurement and simulation of impact wear damage to industrial conveyor belts. Wear. 2016;368:400-7.

17. Fedorko G, Molnar V, Marasova D, Grincova A, Dovica M, Zivcak J, et al. Failure analysis of belt conveyor damage caused by the falling material. Part I: Experimental measurements and regression models. Engineering failure analysis. 2014;36:30-8.

18. Honus S, Juchelkova D, Campen A, Wiltowski T. Gaseous components from pyrolysisCharacteristics, production and potential for energy utilization. Journal of Analytical and Applied Pyrolysis. 2014;106:1-8.

19. She X-f, Wang J-s, Xue Q-g, Ding Y-g, Zhang S-s, Dong J-j, et al. Basic properties of steel plant dust and technological properties of direct reduction. International Journal of Minerals, Metallurgy, and Materials. 2011;18(3):277-84.

20. Bies DA, Hansen CH. Engineering noise control: theory and practice: CRC press; 2009.

21. Zhang H, Tan Y, Yang D, Trias FX, Jiang S, Sheng Y, et al. Numerical investigation of the location of maximum erosive wear damage in elbow: Effect of slurry velocity, bend orientation and angle of elbow. Powder Technology. 2012;217:467-76.

22. Zhu H, Wang J, Ba B, Wu Z, Wang W. Numerical investigation of flow erosion and flow induced displacement of gas well relief line. Journal of Loss Prevention in the Process Industries. 2015;37:19-32.

23. Xie L, Zhong W, Zhang H, Yu A, Qian Y, Situ Y. Wear process during granular flow transportation in conveyor transfer. Powder Technology. 2016;288:65-75.

24. Bhattacharya M, Bhowmick AK. Analysis of wear characteristics of natural rubber nanocomposites. Wear. 2010;269(1-2):152-66.

25. Ravi Kumar BN, Suresha B, Venkataramareddy M. Effect of particulate fillers on mechanical and abrasive wear behaviour of polyamide 66/polypropylene nanocomposites. Materials \& Design. 2009;30(9):3852-8.

26. Suresha B, Chandramohan G, Jawahar MA, Mohanraj S. Three-body Abrasive Wear Behavior of Filled Epoxy Composite Systems. Journal of Reinforced Plastics and Composites. 2008.

27. Pal K, Rajasekar R, Kang DJ, Zhang ZX, Pal SK, Das CK, et al. Effect of fillers on natural rubber/high styrene rubber blends with nano silica: Morphology and wear. Materials \& Design. 2010;31(2):677-86.

28. Dobrotă D. Adhesion degradation of rubber and steel insert for conveyor belts. Journal of Adhesion Science and Technology. 2013;27(2):125-35.

29. Tangudom P, Thongsang S, Sombatsompop N. Cure and mechanical properties and abrasive wear behavior of natural rubber, styrene-butadiene rubber and their blends reinforced with silica hybrid fillers. Materials \& Design. 2014;53(0):856-64.

30. Myshkin NK, Petrokovets MI, Kovalev AV. Tribology of polymers: Adhesion, friction, wear, and mass-transfer. Tribology International. 2005;38(11-12):910-21.

31. Briscoe BJ, Sinha SK. Wear of polymers. Proceedings of the Institution of Mechanical Engineers, Part J: Journal of Engineering Tribology. 2002;216(6):401-13. 
32. Pal K, Pal SK, Das CK, Kim JK. Relationship between normal load and dynamic co-efficient of friction on rock-rubber wear mechanism. Materials \& Design. 2010;31(10):4792-9.

33. Pal K, Das T, Rajasekar R, Pal SK, Das CK. Wear characteristics of styrene butadiene rubber/natural rubber blends with varying carbon blacks by DIN abrader and mining rock surfaces. Journal of Applied Polymer Science. 2009;111(1):348-57.

34. Muhr AH, Roberts AD. Rubber abrasion and wear. Wear. 1992;158(1-2):213-28.

35. Basak AK, Matteazzi P, Vardavoulias M, Celis JP. Corrosion-wear behaviour of thermal sprayed nanostructured $\mathrm{FeCu} / \mathrm{WC}-\mathrm{Co}$ coatings. Wear. 2006;261(9):1042-50.

36. Voss H, Friedrich K. On the wear behaviour of short-fibre-reinforced peek composites. Wear. 1987;116(1):1-18.

37. Harsha AP, Tewari US. Two-body and three-body abrasive wear behaviour of polyaryletherketone composites. Polymer Testing. 2003;22(4):403-18.

38. Trezona RI, Hutchings IM. Three-body abrasive wear testing of soft materials. Wear. 1999;233235(0):209-21.

39. Harsha AP, Tewari US. The Effect of fibre reinforcement and solid lubricants on abrasive wear behavior of polyetheretherketone composites. Journal of Reinforced Plastics and Composites. 2003;22(8):751-67.

40. Budinski KG. Guide to Friction Wear and Erosion Testing. USA: ASTM International; 2007.

41. Harsha AP. An investigation on low stress abrasive wear characteristics of high performance engineering thermoplastic polymers. Wear. 2011;271(5-6):942-51.

42. Xu D. Dry Rolling Friction and Wear of Elastomer Systems and Their Finite Element Modelling: Technischen Universität Kaiserslautern 2009.

43. Pramanik A, Zhang L, Arsecularatne J. Deformation mechanisms of MMCs under indentation. Composites Science and Technology. 2008;68(6):1304-12.

44. Pramanik A, Zhang LC, Arsecularatne JA, editors. Micro-Indentation of Metal Matrix Composite-An FEM Investigation. Key Engineering Materials; 2007: Trans Tech Publ.

45. Karger-Kocsis J, Felhös D, Xu D. Mechanical and tribological properties of rubber blends composed of HNBR and in situ produced polyurethane. Wear. 2010;268(3-4):464-72.

46. Mukhopadhyay A. SEM study of worn surface morphology of an indigenous 'EPDM' rubber. Polymer Testing. 2016;52:167-73.

47. Nayek S, Bhowmick AK, Pal SK, Chandra AK. Wear behavior of silica filled tire tread compounds by various rock surfaces. Rubber Chemistry and Technology. 2005;78(4):705-23.

48. Bateman L, Association NRPR. The chemistry and physics of rubber-like substances : studies of the Natural Rubber Producers. London: Maclaren; 1963.

49. Schallamach A. Abrasion of rubber by a needle. Journal of Polymer Science. 1952;9(5):385-404.

50. Gatos KG, Kameo K, Karger-Kocsis J. On the friction and sliding wear of rubber/layered silicate nanocomposites. EXPRESS Polymer Letters. 2007;1(1):27-31.

51. Fukahori Y, Liang H, Busfield JJC. Criteria for crack initiation during rubber abrasion. Wear. 2008;265(3-4):387-95.

52. Schallamach A. A theory of dynamic rubber friction. Wear. 1963;6(5):375-82.

53. Champ DH, Southern E, Thomas AG. Fracture mechanics applied to rubber abrasion. In: Lee L-H, editor. Advances in Polymer Friction and Wear. Polymer Science and Technology. 5: Springer US; 1974. p. $133-44$.

54. Gent AN, Pulford CTR. Mechanisms of rubber abrasion. Journal of Applied Polymer Science. 1983;28(3):943-60.

55. Zhang SW. Investigation of abrasion of nitrile rubber. Rubber Chemistry and Technology. 1984;57(4):769-78.

56. Liang H, Fukahori Y, Thomas AG, Busfield JJC. Rubber abrasion at steady state. Wear. 2009;266(12):288-96.

57. Thomas AG. Rupture of rubber. V. Cut growth in natural rubber vulcanizates. Journal of Polymer Science. 1958;31(123):467-80.

58. Southern E, Thomas AG. Studies of Rubber Abrasion. Rubber Chemistry and Technology. 1979;52(5):1008-18.

59. Fukahori Y, Yamazaki H. Mechanism of rubber abrasion. Part I: Abrasion pattern formation in natural rubber vulcanizate. Wear. 1994;171(1-2):195-202. 
60. Fukahori Y, Yamazaki H. Mechanism of rubber abrasion: Part 2. General rule in abrasion pattern formation in rubber-like materials. Wear. 1994;178(1-2):109-16.

61. Fukahori Y, Yamazaki H. Mechanism of rubber abrasion part 3: how is friction linked to fracture in rubber abrasion? Wear. 1995;188(1-2):19-26.

62. Coveney V, Menger C. Initiation and development of wear of an elastomeric surface by a blade abrader. Wear. 1999;233-235:702-11.

63. Watson JA, Brown CL, Myhra S, Watson GS. Two-dimensional stick-slip on a soft elastic polymer: pattern generation using atomic force microscopy. Nanotechnology. 2006;17(10):2581.

64. Busfield JJC, Liang H, Fukahori Y, Thomas AG. Modelling the abrasion process in elastomer materials Constitutive model for rubber. London: Taylor and Francis group; 2005. p. 139-43.

65. Petrica M, Badisch E, Peinsitt T. Abrasive wear mechanisms and their relation to rock properties. Wear. 2013;308(1):86-94.

66. Trezona R, Hutchings I. Three-body abrasive wear testing of soft materials. Wear. 1999;233:209-21.

67. Budinski KG. Adhesive transfer to abrasive particles in abrasion testing. Wear. 2011;271(9):1258-63.

68. Tylczak JH, Hawk JA, Wilson RD. A comparison of laboratory abrasion and field wear results. Wear. 1999;225:1059-69.

69. Molnar W, Varga M, Braun P, Adam K, Badisch E. Correlation of rubber based conveyor belt properties and abrasive wear rates under 2-and 3-body conditions. Wear. 2014;320:1-6.

70. Myshkin N, Petrokovets M, Kovalev A. Tribology of polymers: adhesion, friction, wear, and masstransfer. Tribology International. 2006;38(11):910-21.

71. Archard JF. Contact and Rubbing of Flat Surfaces. Journal of Applied Physics. 1953;24(8):981-8.

72. Zum Gahr KH. Microstructure and wear of materials. 1987.

73. Şahin Y. Analysis of abrasive wear behavior of PTFE composite using Taguchi's technique: Cogent OA; 2015. $1000510 \mathrm{p}$.

74. Lancaster JK. Abrasive wear of polymers. Wear. 1969;14(4):223-39.

75. Moore MA. Abrasive wear. International Journal of Materials in Engineering Applications. 1978;1(2):97-111.

76. Unal H, Mimaroglu A, Kadioglu U, Ekiz H. Sliding friction and wear behaviour of polytetrafluoroethylene and its composites under dry conditions. Materials \& Design. 2004;25(3):239-45.

77. Suresha B, Kumar KNS. Investigations on mechanical and two-body abrasive wear behaviour of glass/carbon fabric reinforced vinyl ester composites. Materials \& Design. 2009;30(6):2056-60.

78. Wu YP, Zhou Y, Li JL, Zhou HD, Chen JM, Zhao HC. A comparative study on wear behavior and mechanism of styrene butadiene rubber under dry and wet conditions. Wear. 2016.

79. Budinski KG. Resistance to particle abrasion of selected plastics. Wear. 1997;203-204:302-9.

80. Briscoe BJ, Lin Heng Y, Stolarski TA. The friction and wear of poly(tetrafluoroethylene)-poly (etheretherketone) composites: An initial appraisal of the optimum composition. Wear. 1986;108(4):357-74.

81. Guo Y, Wang J, Li K, Ding X. Tribological properties and morphology of bimodal elastomeric nitrile butadiene rubber networks. Materials \& Design. 2013;52:861-9.

82. Békési N. Modelling Friction and Abrasive Wear of Elastomers2012.

83. Goda TJ. Effect of track roughness generated micro-hysteresis on rubber friction in case of (apparently) smooth surfaces. Tribology International. 2016;93, Part A:142-50.

84. Moore DF. Friction and wear in rubbers and tyres. Wear. 1980;61(2):273-82.

85. Xu D, Karger-Kocsis J, Schlarb AK. Rolling wear of EPDM and SBR rubbers as a function of carbon black contents: correlation with microhardness. J Mater Sci. 2008;43(12):4330-9.

86. Felhös D, Karger-Kocsis J, Xu D. Tribological testing of peroxide cured HNBR with different MWCNT and silica contents under dry sliding and rolling conditions against steel. Journal of Applied Polymer Science. 2008;108(5):2840-51.

87. Zhang SW. State-of-the-art of polymer tribology. Tribology International. 1998;31(1-3):49-60.

88. Purushothaman N, Moore ID. Hysteresis Sliding Friction of Rubber-Finite Element Analysis. Journal of Engineering Mechanics. 1990;116(1):217-32. 